\title{
Which Lane Should We Be In?
}

\author{
Michael A. Ashby • Leigh E. Rich
}

Received: 19 September 2016 / Accepted: 26 September 2016/Published online: 31 October 2016

(C) Journal of Bioethical Inquiry Pty Ltd. 2016

\section{Some Thoughts on Print versus Online, Open Access, and Web Presence: Future Directions for the $J B I$ and Growing Its Global Community}

For some time now, the editorial board (and various subcommittees) of the Journal of Bioethical Inquiry $(J B I)$ has been giving a good deal of thought to some of the major issues that we (and other journals) must work through in the rapidly changing contemporary publishing environment. The evolution of open access publishing and the proliferation of blogs and web-based resources in all areas of life-including the worlds of academia and bioethics - is clear, and we need to come to a consensus about how to situate ourselves in this ever-changing landscape. There would appear broadly to be two lanes of academic publishing operating in parallel. One is the "fast food" online route, where conversations can occur

M. A. Ashby

Palliative Care Service, Royal Hobart Hospital, Tasmanian Health Service, Hobart, Australia

M. A. Ashby $(\bowtie)$

School of Medicine, Faculty of Health Sciences, University of Tasmania, 1st Floor, Peacock Building, Repatriation Centre, 90 Davey Street, Hobart, TAS 7000, Australia

e-mail: michael.ashby@ths.tas.gov.au

L. E. Rich

Department of Health Sciences (Health Services Administration), Armstrong State University, 11935 Abercorn Street, University Hall 154F, Savannah, GA 31419, USA

e-mail: leigh.rich@armstrong.edu almost in real time, and this is particularly relevant to a dialectical field such as bioethics. It is also thoroughly consistent with the JBI's mission to promote international conversations about major bioethical issues that challenge us at home and in the world. However, to date the major strength of the journal has been in the "slow food" lane, in its capacity to promote and curate deep scholarship from a multidisciplinary perspective. The $J B I$ has been particularly successful in its production of symposia and special issues, often cultivated by guest editors and through which in-depth examinations and conversations regarding specific pressing (or even long-standing) bioethical issues have taken place. The journal, however, has not hitherto been a major player in the online scene, and we are mindful that if you are not visible online, your existence in the modern world is questionable!

At the $J B I$ we see our existence as ultimately more than just an academic journal; rather, the $J B I$ aims to foster a community of bioethics scholars and practitioners from multiple disciplines and all corners of the world. To achieve this requires travel via both lanes, and to this end, the $J B I$ has been trying to bridge distances and pick up speed in the virtual realm in order to grow this community, reach more places and cultures, and encourage not just faster but more and better dialogue. Leigh Rich, former editor of the $J B I$ and now a consulting editor (membership in the $J B I$ community is often considered lifetime!), has been working on our web development, and what follows is a summary of where things have reached. 
Through our publisher Springer, the $J B I$ has an online presence via its websites (see http://www.springer. com/medicine/journal/11673 and http://link.springer. com/journal/11673). The first link includes areas such as the $J B I$ 's aims and scope, instructions for authors, access to the Editorial Manager portal for article submissions, and information about the editorial board. The second URL contains information about the journal's impact factor as well as a way to browse volumes and issues and links to individual articles. However, these sites, while important (and we are grateful to Springer for this support), tend toward the utilitarian and do not offer much information about "who" the $J B I$ is.

We therefore decided a few years ago to fund and manage an additional website (see http:// bioethicalinquiry.com/), through which we can better operationalize the journal's goals and offer more than basic information about the journal and its activities. Like so many others in today's day and age, we began in the most cost-effective way possible - purchasing the domain name, paying for basic web hosting services, and using a free platform to help us dip a toe into the electronic ether. A few JBI "lifers" have thus far designed and managed the website, in between juggling other journal tasks and our everyday professional lives.

While the current platform is usable (and we profusely thank everyone who makes the platform and such great templates possible!), we remain unsure whether it will suit our needs - as we further understand exactly what those needs may be and especially as our online presence grows, although even paid platforms have their limitations. The $J B I$ has been using this initial website primarily for promoting and posting: each journal issue's table of contents (with titles, author names, abstracts, and links to articles via Springer's $J B I$ websites); our "In That Case" column that presents real or imagined cases in bioethics as well as responses to them; and other opportunities, events, calls for papers, and some career-related information.

What we have now-an interim support as we proceed further down this path - thus does allow for some interaction and dialogue with, and among, readers via blog-style posting and commenting. However, we want more: more dialogue, more near "real-time" interaction, more connections and commentary and collaborations.

In that vein, the $J B I$ editorial board welcomes your thoughts about how to develop our "fast" lane. "Static" websites, blogs, and Twitter gain and retain few readers and followers. Active and interactive sites are key. We want not just a useful but also a contemplative bioethics website, and one that welcomes individuals "from across the universe"- scholars and teachers, clinicians and administrators, policy-makers and the public. The key is ongoing, quality, up-to-date information, resources, and dialogue. Visions for growing bioethicalinquiry.com into an active and interactive entity - that attempts more "fast-food" timing but ensures "slow-food" quality of thought—will ultimately require new resources, as this work is labour intensive and the current editorial capacity is limited and focused on the ongoing, large task of producing the journal.

Would that resources were never a question, the $J B I$ would like to pursue the possibility of developing an "ethical academic publishing" model, where peerreviewed research and other features could be published in an open access format, without simply shifting the costs of publication from the shoulders of readers and their institutions to that of authors and funders. (And the journal is currently conducting an exploratory feasibility study to this end.) There are issues other than just "pay," however, as a tension exists within academia as to how "impact" can best be measured and what "counts" as publication and thus helps scholars accrue the necessary capital in the "publish or perish" world. Additionally, there is a question of current reach - and providing a reliable platform in multiple languages (though just ask the World Health Organization how challenging this can be!) - as well as longevity and safeguarding and archiving the scholarship of today (for better or worse) for the generations of tomorrow.

As you will all know and no doubt share, the $J B I$ has at the core of its being a heartfelt commitment to global inclusiveness - and much still needs to be done by all of us in this space. English language and logical-positive Anglo-Saxon philosophy dominate the conversation and the means. In upcoming issues of the journal, we will be road-testing a new regular feature entitled the "Global Bioethics Forum." We have selected a paper from a non-English speaking country about an issue of topical importance in that part of the world, through which we all might benefit by being part of a more global movement or conversation. The paper will receive assistance from an in-house language editor (with low-cost recovery from authors), and we will assist with the style and argumentation techniques where needed. When we have agreement with the authors regarding a final version, it will go out for peer review. We will 
assess the venture over the next few issues and hope you will too.

Lastly, we also are reactivating an "In That Case" column involving renal dialysis (Ashby 2015; see http://bioethicalinquiry.com/limiting-kidneydialysis-availability-over-75/), and we encourage you to offer your insights and comments on the website. It was surprising to us that such a controversial suggestion would go unchallenged, as it presented a scenario where ageism and limitation of medical treatment were writ large. The case was prompted by a landmark, and much misunderstood, 2014 article by Ezekiel Emmanuel in The Atlantic, in which he boldly presented the view that we should all question what we expect of life, health, and hence healthcare as we enter the Western "peak dying time" of 75-85 years (Emanuel 2014). Care and decisionmaking at the end of life are ubiquitous topics in bioethics, health policy, clinical literatures, and the global media, but the difficulty seems to be to move from general agonizing, often masked under the umbrella of "complexity," to the personal and specific, as Emmanuel tries to do.

We certainly welcome comments from our readers and the bioethics community at large on all these issues, in the spirit of the global conversation we aspire to be. To contribute your thoughts, please either e-mail the editors at bioethicalinquiry@gmail.com or post a comment at http://bioethicalinquiry.com/limiting-kidneydialysis-availability-over-75/.

\section{Symposium on Disability}

Returning to our "slow lane," this edition of the journal contains a symposium on disability, put together by our colleagues at George Washington University. In reading the papers in the symposium, one of us (MA) was reminded of the observations of the late Helen Bamber, a British pioneer in the field of refugee, torture, and trauma rehabilitation, who as a young welfare worker was present at the liberation of one of the World War II concentration camps and who has pointed out that, after the original horror of the discovery of the camps and outpouring of empathy for the victims, things started to change as time and distance intervened (Belton 1998). Resettlement was a slow process, and many people had nowhere to go. The liberated survivors started to organize and agitate, and at this point they became more of an "irritant" as the original empathy waned. So how do we move from well-meant but unhelpful armchair sympathy (which may be more about ourselves than we care to consciously admit) to a true understanding of those we label "disabled" and their fundamental right to be "engaged citizenry" in the full political and activist sense? The symposium in this issue of the $J B I$ draws attention to a central bioethical theme, namely how we relate to the "other." Unfortunately, in human nature there is a struggle with dealing with difference, at both an individual and a societal level, and one that is ignored at our peril. Difference makes people suspicious and critical about those who do not conform to "accepted" norms of what bodies and lives should be. In bioethics, the task is to analyse these aspects of the human condition and, by a better understanding of each other, lead to a kinder and more inclusive world. The authors in this symposium all share the task of trying to radically reframe how "disability" is seen, as states of being in their own right rather than existences that are lacking in relation to that which the rest of us might have. We hope that this issue will help us all on this collective journey.

\section{Depression and Its Causes: Illness and Society}

It is heartening to see the interview with Ann Cvetkovich, author of Depression: A Public Feeling (2012), striking a counterbalance to the illness model that dominates the modern world and its enormous mental health challenges. Despite all the improvements to lives from progress, technology, and even global labour and capital flows, the price paid in terms of the rapid changes to culture and social structure almost everywhere is largely ignored by the global corporate elites who are leading the charge. So if this is "progress" and some kind of inherent good, why do so many people become mentally ill, opt out, drop out, or turn to drugs and alcohol? Freud tried to understand the dark destructive and indeed self-destructive potential that exists within all human beings, and we all have the capacity to score health-related "own goals" by doing dangerous or harmful things. Any parent, school principal, or doctor ought to be alarmed at the amount of selfharm, suicide, drug and alcohol use, cutting, eating disorders, and the ubiquitous depression we all see around us in modern Western societies. Nobody 
seems to have any coherent idea about why, and refuge is often sought in medicine and science, with better diagnostic detection and clinical awareness, rather than looking more deeply at our lives, societies, and social institutions. Instead of blaming the patient (the citizen), why not ask some questions of the system that has been created? In this respect, Cvetkovich may be seen in some way to be retreading the steps of the so-called anti-psychiatry movement of the mid-twentieth century in the writings of Thomas Szasz (1970) and R.D. Laing (2010). In the headlong rush to medicalize all our personal and social ills, the system forgets that it is also the problem. (Isn't this what Ivan Illich [1976] warned us of four decades ago?) Of course, we should not deny the importance of biological psychiatry, genetics, and treating those who are mentally ill, but there is also a need to make sure that we do not stop looking at ourselves and our societies in the causal chain as well. It seems that if you are struggling with what society does to you, one (probably unconscious) answer is to turn that struggle into an illness and a medical condition that can then be treated. The system, for its part, also just might help that along (complete with new techniques and technologies that these days often aim for profit-generating maintenance rather than prevention or cure). The illness role is then a socially sanctioned space and explanation, from which blame is detached. This is a dangerous and limited dead end. It is part of the role of bioethics to interrogate the system about these problems and the narrowly focused scientific medicalization of our discontentments.

Perhaps part of the problem is that we live in at age of technical possibilities that locates our hopes and aspirations at a level of expectation that is ultimately unrealistic and tries to skate over some of our fundamental human needs and deeper connections. After all, utopia truly is "no place," and it just may be, at this point in human history, that we had higher hopes and that the observed compared to the expected in everyday life is just too much of a mismatch for those who are not winning. Competition, expensive never-ending education, job insecurity, user-pays for everything, constant organizational restructuring. Sound familiar? All these things can have an impact on collective and personal anxiety and well-being. It also just may be that we are winning some kind of battle of the body ... and losing that of the mind.

\section{General Papers and Regular Features}

In an update on the Oshin case in Western Australia (see the Recent Developments column, Richards and Okninski 2016), it is noteworthy that the court ruled that this young boy should not be compelled to undergo radiotherapy for his brain tumour, against parental wishes. Despite differing expert medical opinions, it was concluded that the risks of brain damage as a result of radiation outweighed the poor chance of tumour control. The authors point out that this decision reiterates the legal rule that the preservation of life itself is not absolute. If the burdens of living longer outweigh the benefits, then this is not in the child's best interests. (One of us, MA, apologizes for the error of gender he made in the last editorial: the case concerns a boy, Oshin.)

Three papers similarly examine bioethical issues related to children. Ruhe and colleagues (2016) from Basel address childhood capacity and its historical reliance on notions of fixed cognitive development based largely on the child development stages described by Piaget. The authors present the case for a more contextual and social model for evaluating a child's capacity to participate in decision-making about themselves, dare one say a more "holistic" approach to the subject. Jeremic et al. (2016) argue that rigid legal age parameters may be impairing the involvement of children in decision-making about their treatment, and Wilkinson and Dittmer (2016) argue against the priority given to children for renal transplantation. At first glance this would surprise many people, but this ethical analysis shows that there is no justification for such an automatic assumption, an assumption based no doubt on the (understandable) emotional community response that is usually seen in matters concerning the interests of children.

Additional articles in this issue of the $J B I$ focus on the healthcare provider-patient relationship in general. Any clinician working in a hospital or aged care facility will attest to the common problem of delirium and the challenges of managing it, including dealing with patient autonomy. In a retrospective case study of patients documented as having delirium in a Sydney hospital, Lamont et al. (2016) show that documentation of ethical and consent processes was patchy. This no doubt reflects the uncertainties that clinical staff experience, especially where there is an absence of advance directions or 
even a substitute decision-maker. Dean and colleagues (2016) also write that healthcare spaces can be inhospitable places for lesbian, gay, bisexual, transgender, and queer (LGBTQ) populations. Despite staff training and awareness campaigns, the actual places themselves and the way they function can be unintentionally discriminatory.

The traditional basis of modern medical ethics is focused on the dyad doctor-patient relationship. In reality, of course, the patient is usually surrounded by family, carers, and healthcare teams, especially at the end of life when the patient often also lacks capacity. Health policies and practice have long recognized the need to work with this group, rather than just the patient alone. In hospice and palliative care, it is even stated that the family is the "unit of care." This is because a sick person rarely exists in a vacuum, and where potentially contestable treatment decisions are required, different views about best interests and strong personal bonds and emotions can derail the care plan and lead to "moral distress." Using the work of German philosopher Jürgen Habermas, Walker and Lovat (2016) discuss a "dialogic model of discourse" in decision-making at the end of life based on the need to understand the "other" and "intersubjectivity." It is worth noting that Wilkinson et al. (2016), in a recent article in the journal Bioethics, have argued persuasively on theoretical grounds that what they call "medical dissensus" is healthy and therefore that agreement and consensus have no intrinsic moral worth for end-of-life decisions-making. Whilst this may be so, one of us (MA), as a practising palliative care specialist, would comment that in the process of caring for dying people, consensus, where achievable by "dialogic consensus" building, self-evidently works better than disagreement, for all concerned, and is a major part of this work. Returning to the general research papers in the $J B I$, Reeve et al. (2016) tackle another important aspect of care at the end of life, so-called "deprescribing" for deteriorating patients, especially the elderly. Understanding the altering need for medications that have been accumulated during chronic disease journeys is difficult for many patients, and they are often not active participants in such considerations.

\section{References}

Ashby, M.A. 2015. In that case: Necessary limitation of medical treatment, ageism, or worse? A policy proposal for limiting kidney dialysis availability over 75. Journal of Bioethical Inquiry 12(2): 171-172. http://bioethicalinquiry. com/limiting-kidney-dialysis-availability-over-75/.

Belton, N. 1998. The good listener: Helen Bamber: A life against cruelty. London: Weidenfeld and Nicholson.

Cvetkovich, A. 2012. Depression: A public feeling. Durham, NC: Duke University Press.

Dean, M., E. Victor, and L. Guidry-Grimes. 2016. Inhospitable healthcare spaces: Why diversity training on LGBTQIA issues is not enough. Journal of Bioethical Inquiry 13(4): doi: 10.1007/s11673-016-9738-9

Emanuel, E.J. 2014. Why I hope to die at 75: An argument that society and families - and you - will be better off if nature takes its course swiftly and promptly. The Atlantic, October. http://www.theatlantic.com/features/archive/2014/09/why-ihope-to-die-at-75/379329/.

Illich, I. 1976. Medical nemesis: The expropriation of health. New York: Pantheon Books.

Jeremic, V., K. Sénécal, P. Borry, D. Chokoshvili, and D. Vears. 2016. Participation of children in medical decision-making: Challenges and potential solutions. Journal of Bioethical Inquiry 13(4): doi:10.1007/s11673-016-9747-8

Laing, R.D. 2010. The divided self: An existential study in sanity and madness. United Kingdom: Penguin.

Lamont, S., C. Stewart, and M. Chiarella. 2016. Documentation of capacity assessment and subsequent consent in patients identified with delirium. Journal of Bioethical Inquiry 13(4): doi:10.1007/s11673-016-9741-1

Reeve, E., P. Denig, S. Hilmer, and R. ter Meulen. 2016. The ethics of deprescribing in older adults. Journal of Bioethical Inquiry 13(4): doi:10.1007/s11673-016-9736-y

Richards, B., and M. Okninski. 2016. Regulating "quack" medicine and decision-making for children re-visited. Journal of Bioethical Inquiry 13(4): doi:10.1007/s11673-016-9746-9

Ruhe, K., E. de Clerq, T. Wangmo, and B. Elger. 2016. Relational capacity: Broadening the notion of decision-making capacity in paediatric healthcare. Journal of Bioethical Inquiry 13(4): doi:10.1007/s11673-016-9735-Z

Szasz, T. 1970. The manufacture of madness. New York: Harper \& Row.

Walker, P., and T. Lovat. 2016. Dialogic consensus in clinical decision-making. Journal of Bioethical Inquiry 13(4): doi:10.1007/s11673-016-9743-Z

Wilkinson, T., and I. Dittmer. 2016. Should children be given priority in kidney allocation? Journal of Bioethical Inquiry 13(4): doi:10.1007/s11673-016-9737-x

Wilkinson, D., R. Truog, and J. Savulescu. 2016. In favour of medical dissensus: Why we should agree to disagree about end-of-life decisions. Bioethics 30(2): 109-118. 